\title{
Disabled Peoples Evaluation on Childhood Respite Care Experience
}

\section{Kazuyo Funakoshi ${ }^{1 *}$ and Ikuko Sobue ${ }^{2}$}

${ }^{1}$ Department of Nursing, Faculty of Health Sciences, Kagawa Prefectural University of Health Sciences, 281-1 Murecho-hara, Takamatsu, Kagawa 761-0123, Japan

${ }^{2}$ Division of Nursing Science, Graduate School of Biomedical \& Health Sciences, Hiroshima University, 1-2-3 Kasumi, Minami-ku, Hiroshima 7348553, Japan

\section{Abstract}

Aim: We interviewed the disabled adults to establish how respite care can help disabled children to become independent.

Methods: Informed consent was obtained from each of the five participants who are disabled adults. They were interviewed in depth about their experiences of childhood respite care. The analysis was restructured into subcategories and categories with the consideration of the developmental stage of the participants, focusing on the context that led to the assessment and the problems of respite care. This study was carried out upon approval from the ethics committee of the author's institution.

Results: The participants' respite care experiences began with "difficulties of receiving care from nonparent caregivers" in their elementary/junior high school years to "getting to know the worker(s) they could trust" and "making friends for life". From their high school years onwards, respite care started to become the opportunity to "choose their caregivers", "interact with their seniors with the same disabilities and build hopes for their own future" and "continue training towards their independence". Furthermore, it transpired that the participants' outlook on respite care reached the current status of "living with hope" via "understanding of and conflict with parents' feelings" in their elementary to high school years and "emotional independence from parents" in their high school years.

Conclusion: The study showed that disabled children could earn their abilities of "care management" and "social living" and build the chance of "independence from parents" through the use of respite care. This result points to the educative contribution of respite care to the development and independence of disabled children.

\section{Introduction}

Of the 3.663 million disabled people in Japan, only 87,000 live permanently in care facilities, the majority living at home. Similarly, of the 98,000 disabled children under the age of 18 , only 5,000 live in the facilities, meaning the majority of them live at home with their parents and family members.

For disabled children, the preparation for independence is a significant issue to ready themselves for the ageing and death of their parents. From their childhood, these children need to accumulate enough social experiences, so that they can meet their own needs supplemented by the help of others. Therefore, the independence support for them has to be something of which they can take full advantage, and from which they can voluntarily make choices about their future life $[1,2]$. Respite care is an opportunity for social experience and for a guaranteed development for the children to interact with people outside their family. As an opportunity for the independence support for the children, their mothers expect respite care to "prepare their children for future independence", which leads to their "social participation" as an outcome [3]. As pointed out [4], the limitation in the living environment of the disabled arises not from the lack of abilities but from the lack of opportunities, and being able to recognize the value of respite care from the point of future independence would give them a footing for their future. For the disabled children receiving care from their families at home, it is predicted that the respite care experience will lead to their developed abilities of "care management" and "social living". We believe it is vital that the educative support for the independence of these children is developed in view of not only the current, but also the future support for them.

Conventional studies of respite care, however, tended to focus more on the needs and views of parents and supporters, while they hardly looked into it from the disabled children's points of view. Thus in this study we interviewed disabled adults to establish the benefits of respite care in disabled children becoming independent, in order to obtain the materials concerning educative support for them.

\section{Method}

\section{Study design}

A qualitative and inductive study based on in-depth interviews.

\section{Participants}

The participating subjects of this study are disabled adults (20 years or older) who could cooperate in the study at their own will. As adults they are already at the developmental level necessary to abstract and articulate their experiences, and we deemed it more appropriate to work with them to obtain higher quality data concerning the influences of the childhood respite care experience on self-formation, and its merits and demerits. Also if the participants were disabled minors (who must be accompanied by their guardians) and their families, the research into the current usage situations may prove stressful for both parties and could put a strain on the families. With the disabled adults, it is not necessary for them to be accompanied by

"Corresponding Author: Mrs. Kazuyo Funakoshi, Department of Nursing, Faculty of Health Sciences, Kagawa Prefectural University of Health Sciences, 281-1 Murecho-hara, Takamatsu, Kagawa 761-0123, Japan, Tel: 81-87-8701212; E-mail: funakoshi@chs.pref.kagawa.jp

Citation: Funakoshi K, Sobue I (2016) Disabled Peoples Evaluation on Childhood Respite Care Experience. Int J Nurs Clin Pract 3: 175. doi: http:// dx.doi.org/10.15344/2394-4978/2016/175

Copyright: (c) 2016 Funakoshi et al. This is an open-access article distributed under the terms of the Creative Commons Attribution License, which permits unrestricted use, distribution, and reproduction in any medium, provided the original author and source are credited. 
Citation: Funakoshi K, Sobue I (2016) Disabled Peoples Evaluation on Childhood Respite Care Experience. Int J Nurs Clin Pract 3: 175. doi: http://dx.doi. org/10.15344/2394-4978/2016/175

Page 2 of 6

guardians, and even if they were in attendance, as we would be asking about the past experiences, emotional pressures and conflicts would be reduced. The recruiting criteria were as follows:

1. Normally lives at home

2. Experienced short-term facility stays and/or temporary daycare services

3. Registered class 1-2 disabilities (class 1: full-body disability; class 2: significant physical disabilities) and needing living assistance [5,6]. If mental disabilities are also present, around class B (slight mental disability) of the rehabilitation certificate[5,6].

4. Adults (20 years or older) who are able to communicate linguistically (if speech is limited, able to communicate via alternative media)

5. Understands the aim of the current study and able to give consent of cooperation at own will

\section{Methods of recruiting participants}

In year 2012, we approached the "Disabled Living Assistance Centre B" in prefecture A after obtaining informed consent for a recommendation of participants, and received the recommendation for three candidates. Thereafter through snowball sampling, we found five participants who have agreed to take part in the study.

\section{Content of the interviews}

The interviews consists of questions on the participants' impressions, emotions and thoughts of their childhood respite care experiences (short-term stays and temporary day-care usage experiences), and the requests for respite care.

\section{Methods of analysis}

The interviews were taped and fully transcribed. Personal data contained in the audio records was anonymized. Focusing on the contexts that lead to the assessment and the issue of respite care, coherent contexts were sampled from the original data as codes. The codes were grouped into categories and subcategories according to their similarities of significance. They were further restructured, taking into account the participants' developmental stages. The analysis was supervised by specialists in the childcare and welfare fields, as well as those experienced in qualitative research.

\section{Ethical Considerations}

The participants were briefed in writing and verbally on the following points and we obtained written agreements:

\section{- privacy protection;}

- agreeing to take part or not, or withdrawing from the study after agreeing at free will would not in any way disadvantage them;

- the potential benefit of publishing the results for society.

This study was carried out upon approval from the ethics committee of the author's institution.

\section{Results}

All of the five participants are male and in their 20s with class 1 disabilities (Table 1). One of them has spina bifida, the other four have cerebral palsy. Two of them started using short-term facility stays at lower elementary school age and three of them, in junior high school.

\section{Assessments of childhood respite care experiences according to developmental stages}

The participants' outlook on respite care experiences began with "difficulties of receiving care from non-parent caregivers" in their elementary/junior high school years and moved onto "getting to know the worker(s) they can trust" and "making friends for life". From their high school years onwards, respite care started to become an opportunity to "choose their caregivers", "interact with their seniors with the same disabilities and build hopes for their own future" and "continue training towards their independence". Furthermore, it transpired that the participants' outlook on respite care reached the current status of "living with hope" via "understanding of and conflict with parents' feelings" in their elementary to high school years and "emotional independence from parents" in their high school years, summarized in the nine main categories above. Below, the main categories are shown in [ ], the subcategories in [ ], and the main codes in italics.

\section{[ Difficulties of receiving care from non-parent persons](Table 2)}

For those disabled children at elementary/junior high school age, respite care experiences were accompanied by [stress and anxiety arising from unfamiliarity] caused by being cared for by non-parent caregivers, hence at first their response was to wait passively for the caregivers to approach them. Asking for assistance caused them anguish and trouble, and they would even have a feeling of dislike toward the caregivers.

\section{[Stress and anxiety arising from unfamiliarity]}

- When little, waking up in the facilities in the morning would make them feel confused not knowing where they were.

- First time using the service, cried on hearing parents' voice over the phone.

\begin{tabular}{|l|l|l|l|l|l|l|}
\hline & Age & Sex & Disability level & Conditions & Work & Services currently used \\
\hline A & 22 & M & Category 1 Class 1 & Cerebral palsy & Y & $\begin{array}{l}\text { Short stay, temporary day assistance, mobility } \\
\text { assistance }\end{array}$ \\
\hline B & 22 & M & Category 1 Class 1 & Cerebral palsy & N & $\begin{array}{l}\text { Short stay, temporary day assistance, mobility } \\
\text { assistance }\end{array}$ \\
\hline C & 22 & M & Category 1 Class 1 & Spina bifida & N & $\begin{array}{l}\text { Short stay, temporary day assistance, day } \\
\text { service with bathing }\end{array}$ \\
\hline D & 27 & M & Category 1 Class 1 & Cerebral palsy & Y & Helper service, mobility assistance \\
\hline E & 23 & M & Category 1 Class 1 & Cerebral Palsy \& hydrocephalus & Y & Short stay, job assistance \\
\hline
\end{tabular}

Table 1: Background of the participants.

* Based on the physical disability certificate or rehabilitation certificate $[5,6]$. 
Citation: Funakoshi K, Sobue I (2016) Disabled Peoples Evaluation on Childhood Respite Care Experience. Int J Nurs Clin Pract 3: 175. doi: http://dx.doi. org/10.15344/2394-4978/2016/175

Page 3 of 6

\begin{tabular}{|c|c|c|}
\hline Categories & Subcategories & Period \\
\hline $\begin{array}{l}\text { Difficulties of receiving } \\
\text { assistance from non-parent } \\
\text { caregivers }\end{array}$ & $\begin{array}{l}\text { Stress and anxiety arising from unfamiliarity } \\
\text { Difficulties of asking for assistance } \\
\text { Distress arising from asking for assistance } \\
\text { Hesitation and fear towards certain workers } \\
\text { Dislikes towards certain workers }\end{array}$ & $\begin{array}{l}E-J \\
E \\
E-J \\
E-J \\
E\end{array}$ \\
\hline $\begin{array}{l}\text { Getting to know the worker(s) } \\
\text { they can trust }\end{array}$ & $\begin{array}{l}\text { Enjoyable rapport with workers } \\
\text { Workers' relaxing demeanors } \\
\text { Willingness to use the facility again } \\
\text { Workers' support on studies and life learning } \\
\text { Choosing the facilities with trusted workers }\end{array}$ & $\begin{array}{l}\text { mainly J } \\
\text { E - mainly J } \\
\text { J } \\
\text { J - H } \\
\text { H }\end{array}$ \\
\hline Making friends for life & $\begin{array}{l}\text { Place of friendly interactions outside school } \\
\text { Developing the sense of solidarity } \\
\text { Interacting with ingenuities, accepting differences of disabilities } \\
\text { Making long-term friends }\end{array}$ & $\begin{array}{l}\text { E - J } \\
\text { J } \\
\text { E- J } \\
\text { H - Current }\end{array}$ \\
\hline Choosing caregivers & $\begin{array}{l}\text { Choosing workers from whom to ask for assistance } \\
\text { Asking for assistance based on own observations on what is needed for themselves } \\
\text { Can also consider the caregivers' standpoints }\end{array}$ & $\begin{array}{l}\mathrm{J}-\mathrm{H} \\
\mathrm{H} \\
\text { Current }\end{array}$ \\
\hline $\begin{array}{l}\text { Interacting with their seniors } \\
\text { with the same disabilities and } \\
\text { building hopes for their own } \\
\text { future }\end{array}$ & $\begin{array}{l}\text { Opportunities to interact with slightly older people who are aiming to become } \\
\text { independent regardless of their disabilities } \\
\text { Coming up with future targets }\end{array}$ & $\begin{array}{l}\mathrm{H} \text { - post grad. } \\
\mathrm{H}\end{array}$ \\
\hline $\begin{array}{l}\text { Opportunities to continue } \\
\text { training for independence }\end{array}$ & $\begin{array}{l}\text { Using respite care for training purposes } \\
\text { Managing life plans by themselves using respite care } \\
\text { Able to act according to their own judgment }\end{array}$ & $\begin{array}{l}\mathrm{H} \\
\text { Post H grad. - current } \\
\text { Current }\end{array}$ \\
\hline
\end{tabular}

* E, J, H, grad. denote respectively "elementary school period", "junior high school period", "high school period", and "graduation".

Table 2: Process of disabled children obtaining abilities in care management and social living.

\section{[Distress arising from asking for care]}

- Made to feel sad as it was not easy to successfully ask for care from some less approachable workers

- Made to feel sad as there were some workers who got angry if not enough urine each time.

\section{[Difficulties of asking for care]}

- Without taking their own initiative to call the workers, they were not given assistance.

- Even asking for the same assistance would result in different responses depending on the workers, and there were ones who were not very approachable.

\section{[Hesitation and fear towards certain workers]}

- Wanted to get off the wheelchair but felt hesitant and could not say so.

- $\quad$ On the first day using a facility, splashed shower on a worker at bathing time and felt scared.

\section{[Dislikes towards certain workers]}

- Hated the workers who would say "it's inconvenient having to take you to the toilet too often".

- It was in the end ok if they did take you to the toilet, but still hated the fact that they said "you go to toilet too often".

\section{[Getting to know the worker(s) they can trust]}

In their elementary/junior high school years, the children experienced the thawing of tension through meeting the workers they could trust and this led to enjoyable living experiences. These experiences further brought about the feeling that they themselves wanted to use the facilities, and affected the choice of future facilities. Thus, getting to know the worker(s) they can trust within respite care signified an opportunity to bridge the sense of security into the future.

\section{[Enjoyable rapport with workers]}

- $\quad$ There were many different people there and found that exciting.

- $\quad$ Playing with the workers was fun.

- Felt at home and thought it was a great place.

[Workers' relaxing demeanors]

- Felt relieved as a worker talked to me really kindly.

- Felt I should be happier as a worker was helping me right by my side.

[Willingness to use the facility again]

- It was fun so I felt I wanted to go again.

[Workers' support on studies and life learning]

- A worker helped me with my studies and assisted me with the personal computer settings I could not do alone.

- $\quad$ A worker helped me practice for exams and interviews.

\section{[Choosing the facilities with trusted workers]}

- $\quad$ Our facility choice is strongly affected by its workers. There are many occasions when human relationships and interactions become difficult for us and talking to certain workers (whom we trust) makes us feel better, so I still talk to those people when there are problems. 
Citation: Funakoshi K, Sobue I (2016) Disabled Peoples Evaluation on Childhood Respite Care Experience. Int J Nurs Clin Pract 3: 175. doi: http://dx.doi. org/10.15344/2394-4978/2016/175

Page 4 of 6

- I chose the facility to go to after graduating from high school where I met a worker I could trust on a short-term stay.

\section{[Making friends for life]}

Respite care during their elementary/junior high school years provides the disabled children with opportunities to interact with friends outside school and to develop social skills. Also, the strong friendships forged through these experiences lead to their acquiring friends for life.

\section{[Interacting with ingenuity, accepting differences of disabilities]}

- We try to be inventive when communicating with people who cannot verbally communicate, but at the same time we realize its difficulties.

\section{[Place of friendly interactions outside school]}

- Having friends to play and study with was fun.

- Felt happy to be able to make friends to talk to, normally not possible at school.

\section{[Developing the sense of solidarity]}

- Participating in team games enabled us to make "buddies" to do fun activities together.

\section{[Making long-term friends]}

- A friend from a short-stay while in elementary school came to the same high school as me, and that made it easier to get used to the school more naturally.

- Having friends with whom I can share memories.

\section{[Choosing caregivers]}

In their high school years, the children started to make their own decisions about who to ask for help and what assistance was needed.

[Choosing workers from whom to ask for care]

- It was not nice to be criticized so started to avoid unapproachable workers and instead look for others.

- Became increasingly able to choose which workers to ask for assistance.

[Asking for assistance based on own observations on what is needed for themselves]

- Felt my standing posture was not secure and potentially hazardous so used to ask the workers for help.

- $\quad$ Able to ask for assistance after thinking how much I can do myself and/or how much actual assistance is needed.

[Interacting with their seniors with the same disabilities and building hopes for their own future]

Meeting slightly older people in respite care in their high school years gave the disabled children an opportunity to ponder upon their own future, precisely because they shared the same disabilities. And, they would start to form more concrete and achievable goals for the future, and build confidence to work towards these goals.

[Opportunities to interact with slightly older people who aim to become independent regardless of their disabilities]

- Met a university student with disabilities and got to talk a lot, and gave me a lot of advice.

\section{[Coming up with future targets]}

- Started to think about going to university.

[Opportunities to continue training towards independence]

Respite care use from high school years onwards started to become training opportunities continued from their daily routine. The children would understand their tasks and actively engage in the training. They were happy that reaching their age meant that they could make their own decisions in daily living, while feeling discontent about the potential inconveniences of not being able to control the situation when their environment becomes less than adequate.

\section{[Using respite care for training purposes]}

- $\quad$ Continued training in daily activities

- Intensive walking training

[Managing life plans by themselves using respite care]

- Based on the advice from the high school period, started to make plans for life after graduation while discussing with mother.

- With clear aims in mind, made plans for what I wanted to do, while asking questions about things I did not understand.

[Able to act according to their own judgment]

- Living by own judgment is fun.

- While there are more things I can do on my own as long as the environment is right, I feel the inconveniences of being affected by that very environment.

[Understanding of and conflict with parents' feelings] (Table 3)

In their elementary/junior high school years, the disabled children would feel unhappy when the parents did not explain the reasons why they were using respite care, even when they could understand the parents' situation. In their high school years, they started to recognize using respite care as something unavoidable according to the parents' needs.

[Did not understand as reasons of use not explained]

- $\quad$ Parents never explained why.

- Never known the reasons, and even to this day I don't know.

[Reasons did not matter too much as long as it was fun]

- $\quad$ Better to use respite care as I hated school work.

- It was fun meeting lots of friends there so when parents mentioned respite care I used to say "sure". 


\begin{tabular}{|l|l|l|}
\hline Categories & Subcategories & Period \\
\hline $\begin{array}{l}\text { Understanding of and conflict with parents' } \\
\text { feelings }\end{array}$ & $\begin{array}{l}\text { Did not understand as reasons of use not explained } \\
\text { Reasons did not matter too much as long as it was fun } \\
\text { Understanding of and conflict of feelings towards parents' situations }\end{array}$ \\
\hline $\begin{array}{l}\text { Emotional independence from parents } \\
\text { Living with hope }\end{array}$ & $\begin{array}{l}\text { Able to communicate their feelings about the use } \\
\text { E - J } \\
\text { J - H }\end{array}$ \\
$\begin{array}{l}\text { Table 3: Process of disabled children becoming independent from the caregivers' standpoints } \\
\text { Concrete wishes for further independence }\end{array}$ & H \\
\hline
\end{tabular}

[Understanding of and conflict of feelings towards parents' situation]

- Felt it was fair enough that we had to use respite care when parents had things to do.

- I remember only talking about friends but not about the workers, fearing parents might react angrily.

\section{[Emotional independence from parents]}

From the high school years onwards, the children started to become able to express their wishes about the use of respite care, at the same time experiencing a mixture of understanding and conflict over the parents' permanent situation.

\section{[Able to communicate their feelings about the use]}

- $\quad$ Parents would understand when I told them that I didn't want to use it every time.

- $\quad$ After starting to express my feelings against going to the facilities, I started to ask the reasons behind the use of respite care.

\section{[Living with Hope]}

Currently the participants demonstrate care management abilities - the abilities to ask for caregivers' help while understanding their feelings - and have hopes for their further independence.

\section{[Considerations from the caregivers' standpoints]}

- When small, I would take toileting, bathing and changing clothes etc. for granted during the short stays at the facilities and did not think about the feelings of the caregivers but now as an adult, I can understand the feelings of the caregivers.

\section{[Concrete wishes for further independence]}

- Would rather live at home using the services than at a facility.

- Would like to get to know various people outside.

- Would like to try different new things.

\section{Discussion}

In this study, the contribution of respite care towards disabled children becoming independent is considered from the points of gaining the "care management abilities" and "social living abilities" as well as "independence from parents", with special focus on the developmental stages from the elementary school through to (current) adulthood. The benefits of respite care in terms of educative assistance are also discussed.

\section{Contribution towards gaining care management abilities}

All the participants of this study are severely disabled adults who need almost total assistance in their daily lives. They experienced life at the facilities when their parents - their chief childhood caregivers were not able to provide care and had to use respite care. For them, it would be a stressful experience arising from [difficulties of receiving care from non-parent caregivers] for the first time. It seems quite natural that they reacted variously to the workers' responses with [difficulties of asking for care], [distress arising from asking for care] as well as [hesitation and fear towards certain workers] and [dislike towards certain workers].

On the other hand, [getting to know the worker(s) they can trust] gave them opportunities to become freer from stresses, leading to conquering their difficulties. Therefore, for the disabled persons of elementary/junior high school age, respite care in which they received assistance from non-parent caregivers meant a social experience consisting of both negative and hard, as well as positive encounters. By accumulating the respite care experiences, these children would begin to see the meanings and solutions in these experiences and gradually acquired the abilities to survive.

Through these experiences, by the time they reached high school age, they were increasingly able to [choose caregivers] by themselves observing the workers' situations, making their own decisions on "choosing which workers to ask for assistance" and "asking for assistance after thinking how much I can do myself and/or how much actual assistance is needed". The participants who were also receiving the independence training at their high schools regarded the respite care as the [opportunity to continue training towards independence].

They continued their school training in daily activities such as toileting and walking even when in respite care. Through their own judgments, they continued their training in respite care anticipating the life assisted by non-family members. This result suggests that respite care can be utilized as an educative ground for gaining care management abilities.

\section{Contribution towards gaining social abilities}

The respite care experience gave the participants the opportunities to [make friends for life]. For them, respite care proved to be a "fun" place of interaction with friends, where they made new friends and meeting "buddies" to do things together in teams. Of course they would occasionally quarrel over little things but the experiences actually helped them to nurture their bonds further. The teenagers with special needs such as these disabled children are not always able to benefit from leisure activities [7]. Minkes reports that respite care often provides disabled children with wide-ranging activities and enables them to make friends with staff members and other disabled 
children, making it a positive experience for them [8]. The results of this study and the views such as Minkes' suggest the usefulness of respite care towards acquiring social abilities.

Having reached adulthood, "having friends with whom they can share their memories" in using the same facilities is proof that respite care provided opportunities to understand others, deepen their friendship, and make lifelong friends.

Also they were given the chance to get to know slightly older people with the same disabilities through respite care. These experiences led them to [build hopes for their own future], such as "starting to think about going to university". Respite care experiences can indeed present opportunities to encounter people such as their seniors and friends that daily life through homes and schools are not able to provide. In living, playing and chatting with other disabled children in the same space, a child can build precious relationships for the future through respite care, and in turn these experiences would strengthen their chances of continuing on their chosen paths in the future.

\section{Independence from parents}

For disabled children who are significantly reliant on their parents nursing, [emotional independence from parents] is the biggest issue. In their elementary school period, the disabled children were using respite care "without understanding the reasons" as told to do so by their parents. At junior high/high school age however, they were trying to understand and accept their parents' situation while experiencing a conflict, thinking "sometimes one could not help if parents needed to do other things". Eventually after graduating from high schools, they became more able to "communicate their feelings to them" though the conflict did not disappear. This process shows that respite care can be a learning opportunity in maintaining a sense of distance from parents.

\section{Respite care as educative support}

The results of this study show that respite care is a life experience for disabled children in which they entrust non-family members with theircare, and it can be utilized as an educative ground for them to obtain care management abilities. Furthermore, it offers opportunities to disabled children to interact with people other than their parents and teachers, build future friendships, and learn how to maintain a sense of distance from parents. From these results, the author believes that respite care is beneficial for disabled children as a place with educative functions towards independence.

\section{Conclusion}

This evaluation of respite care experiences of the five people with severe disabilities indicates that using respite care enables them to acquire "care management abilities" and "social abilities", and fosters the possibility of "independence from parents". The results suggest the educative benefit of respite care in the development and independence of disabled children.

\section{Competing Interests}

The authors have no competing interests with the work presented in this study.

\section{Author contributions}

Kazuyo Funakoshi and Ikuko Sobue contributed to the conception and design of the study. Kzuyo Fnakoshi contributed to the acquisition, analyses, and interpretation of the data, as well as the drafting of the manuscript. Ikuko Sobue contributed to the supervision of the drafting and critical revision of the manuscript. All the authors have read the manuscript and have approved this submission.

\section{Acknowledgement}

We are very grateful to all those who participated in this study.

\section{References}

1. Morisaki $\mathrm{H}$ (2005) Recent trends in Japan concerning the independence support for severely disabled children and adults: focusing on "individual transition support plans" at schools for children with physical disabilities, Jpn J Spec 43 (2): 149-157.

2. Takashima K (2007) Concept of "independence" in the education of children with special needs. Nagasaki Int Univ Rev 7: 187-196.

3. Hase M (2008) Review of Publications Concerning the Respite Care of Mothers with Severely Disabled Children in Japan. JSMID 33 : 339-345.

4. Firth H, Rapley M (1990) From Acquaintance to Friendship: Issues for People with Learning Disabilities, British Institute of Mental Handicap Publications, Kidderminster.

5. Ministry of Health, Labour and Welfare. (2008) Grade of handicapped.

6. Crayonbox (2016) Table of disability grades.

7. Timmons V (1993) Quality of Life of teenagers with Special Needs, Unpublished doctoral thesis, University of Calgary.

8. Minkes J, Robinson C, Weston C (1994) Consulting the children: Interviews with children using residential respite care services, Disabil Soc 9(1): 4757. 